\title{
The European Union Digital Single Market-Challenges and Impact for the EU Neighbourhood States ${ }^{1}$
}

Katrin Nyman-Metcalf

\author{
Tallinn Law School, \\ Tallinn University of Technology \\ Akadeemia tee 3 , \\ Tallinn 12618, Estonia \\ E-mail: Katrin.Nyman-Metcalf@taltech.ee \\ loannis F. Papageorgiou \\ Aristotle University of Thessaloniki, \\ Faculty of Economics and Political Sciences, \\ School of Political Sciences \\ Economics and Political Sciences Building, \\ Thessaloniki 54124, Greece \\ E-mail: ipapageo@polsci.auth.gr
}

Abstract: The digital single market is one of the most important objectives and challenges for the European Union. However, given that digitalisation implies a borderless world it requires a different form of governance and has distinctive features from other aspects of the single market. In addition, it raises a number of practical and political issues for countries outside the EU, but which maintain close economic and trade relations with the latter. The article examines the regulatory implications of the digital world from the point of view of states involved in the European Neighbourhood Policy, in particular Georgia, and looks into the future challenges in this process.

Keywords: digitalisation, EU single market, Georgia, neighbourhood policy

1 This article has been prepared in the context of the project LMIN16092 entitled "Digital Single Market as a Key Element in EU-oriented Georgian Higher Education" led by the Tallinn University of Technology with the funding of the Estonian Development Cooperation. 


\section{Introduction}

The EU has, since its inception as the European Communities in 1957, but especially since 1987 and even more comprehensively since 1992, acted to set in place a single market. The term describes the establishment, within the $\mathrm{EU}$, of one territory without any internal borders or other regulatory obstacles to the free movement of goods and services. The establishment of the single market is one of the most significant achievements of European integration and despite the fact that it is still not complete, it has led to a significant increase of European GNI. Since 1992 it has been estimated that the European Single Market raised EU GDP by 5\% (EPRS, 2014).

Since the early 2000s and in the wake of the internet revolution, the EU strives to set a specific set of rules for the single market in the digital area. The early development of the digital market showed evidence of how, rather paradoxically, this market where national borders should not play any role suffered from more obstacles than the traditional EU single market. We can buy our airline ticket or software from any country, hardly even knowing which country it is. For physical goods, there will still be the question of transport, but increasingly many purchases have no physical element-we do not need a DVD or book to be sent but can get the relevant code. With increasing 3D printing, this will be the case for far more products. However, obstacles have been created by intellectual property rules, different rules for licensing of content, geo-blocking, obstacles to delivery of goods bought online, and so on.

The growing awareness within the EU of the obstacles for a functioning digital single market at a time when the digital market as such only increases in importance has led to multiple EU initiatives to create a strategy for the digital single market. Gradually these rules have significantly augmented and cover a wide range of activities, services and rights for consumers, citizens and businesses-perhaps the most complete and comprehensive set of rules for the digital market anywhere in the world. The best-known element and a cornerstone of this process has undoubtedly been the General Data Protection Regulation (GDPR) (Regulation (EU) 2016/679), which entered into force in May 2018. The EU, however, has also gone further than just regulating the existing market and looks to future issues. In this context, the EU has even developed a strategy for artificial intelligence, which among other things contains a charter on the ethics of artificial intelligence.

The digital single market rules of the EU have a wide impact even outside the EU-something which demonstrates the capacity of major trade players to 
set rules at a global level. This is even more true for the states that are in the periphery of the EU and are linked to it with a set of trade and political relations in the context of the EU Neighbourhood Policy (ENP). The implications of the new way to make rules, of the way to take into account how different the digital world may look compared to the "real" one, is something where the EU's effect on its neighbourhood is more diffuse; there are, however, signs of influence in this respect as well.

The objective of this article is to examine the impact, whether immediate or potential, of the EU digital single market on ENP partner states-primarily Georgia-from a qualitative and regulatory viewpoint, including indirect issues (political, economic, technological, ethical and jurisdictional) and more direct ones related to the establishment of deep and comprehensive free trade agreements including regulatory alignment. This addresses the wider question of the ability of the EU to become a relevant global rule-maker for the digital world. We do not provide a full analysis of the substance of the various initiatives of the EU in the digital sphere, but rather we demonstrate how these initiatives can have an impact on domestic relevant policies in ENP countries like Georgia while strengthening the role of the EU globally and in its neighbourhood.

\section{The digital world: regulatory implications of digitalisation}

Internet has profoundly changed society. The legal system sometimes appears to act like an ostrich and thinks that consumer protection law, regulation, prohibitions or age limits related to certain products can keep going in the same way as 20 or 30 years ago. Rules can be made in novel ways (like in multistakeholder fora) but enforcement is still largely state-centric and it is at this point that the inability to make rules internationally surfaces (Morgan \& Yeung, 2007, p. 329). Cyberspace abounds with such examples.

The ease with which national borders can be avoided means that the jurisdictionbased legal system may not withstand the pressures and it may not be enough to try to adapt existing rules, which is what has mainly been the approach so far (Duvivier, 2013, p. 48; Dutt \& Kerikmäe, 2014, pp. 286-287). It is known that legal systems move rather slowly and tend to have a conservative effect, due to the nature of law-making, which is rarely rapid simply because of the various steps the process consists of and that are there to guarantee against ill-thought-through decisions based on political whims. The slowness is thus at least to some extent intentional and gives the legal system the possibility to 
have a stabilising effect, supporting legal certainty and predictability. However, albeit intentional, slowness can be a problem in a fast-moving high-tech world. The question of what should come first, the technology or the regulation, is a classical chicken-or-egg dilemma (Nyman Metcalf, 2014, p. 37). Evidently, we cannot regulate something we do not know, so to some extent technology must come first. At the same time, if technology develops too far in an unregulated way, it is very hard to regulate it later-to put the genie back into the bottle (of which internet is the best illustration).

According to many commentators (inter alia Duvivier, 2013; Nyman Metcalf, 2018), whether in academic or other articles or in the various fora for discussion about the influence and governance of new technologies, what can be done to deal with this dilemma is to create frameworks and systems rather than detailed rules. If we cannot deal with very new technological issues, the extent and consequences of which are not yet known, we can be helped by having a frame in which to place these "unknowns". As far as EU rulemaking is concerned, this way of thinking in broad terms has existed for some time, through the approach to determine desired results rather than details of technical or similar requirements. The approach, which for a long time was referred to as the "new approach", was launched in 1985 when it was seen that the previous practice of detailed technical requirements led to rules being outdated and obsolete even before they entered into force (CEN, 2018).

Rulemaking in the "digital world" poses new challenges. The environment for both making rules and applying them has become interdisciplinary. Technology moves so rapidly that evaluating potential effects through empirical studies may not be enough. Legislative and regulatory work should borrow ideas from, for example, IT research, like modelling. Ideas are tested, if not empirically as there may be no real environment for the study of something experimental and new, then by acting through a scenario. In this way, it is possible to bring the theory to the real world to test its viability. This can be very useful and interesting, but it may also become superficial and pointless if not based on the proper methodology. It may run into the same problems as those that quantification encounters if excessively introduced into the legal field. It is difficult to quantify many of the elements that underlie legislative considerations: what makes people obey rules, what makes some people behave more ethically than others, which sanctions are the most likely to affect behaviour? Having to quantify such abstract matters leads to absurd situations where there is an expectation that it is possible to say how many persons became how many percent less corrupt or more efficient in a set period of time! As this is impossible, there is a trap of bureaucratic quantification instead, showing that so many new rules have 
been adopted. The EU is aware of this risk and has introduced criteria for its regulatory activities that aim to avoid overregulation (Nyman Metcalf \& Täks, 2013, p. 13).

The diffuse nature of borders in the digital world does not only affect the national borders but also borders between categories of services and products, such as between military and civilian. This is an essential issue for the EU as it lacks capacity over military issues. The question of dual-use goods or services existed before the Information and Communication Technology (ICT) era. However, modern technologies have in many ways pushed the border and made it even less clear what is military, as so many technologies developed (and even operated) by the military may be important and frequent in civilian use-GPS being perhaps the best-known example. An opposite development can also be seen, with communications tools developed in the civilian world being so good that the military has no need to develop separate ones. Cyber security, one of the key concerns in modern society, illustrates the blurring of borders very well. In fact, different people mean different things when speaking of cyber security, ranging from purely military concerns to wholly civilian ones, but most correctly it should be an amalgamation of any aspects that can influence the security of our activities in cyber space (Geiss \& Lahmann, 2013, pp. 621-622; Caliskan \& Peterson, 2013). The Cyber Security Index (http://ncsi.ega.ee), developed by the Estonian e-Governance Academy, is a good illustration of what issues matter for cyber security. When looking at the different indicators, they include existence of laws, rules and relevant organs as well as capacity to detect and defend.

Given the importance of cyber security in the modern society, any efforts of the EU in this context are likely to have effect beyond its borders, not least for countries it closely cooperates with, such as the ENP states. Indeed, it may even be via measures for cyber security that the digital agenda of the EU will have the strongest impact - provided that the EU manages to provide relevant tools. Until now, the European efforts in this context are important in the form of the so-called Budapest Convention, the only major international instrument for cybercrime, but this is a product of the Council of Europe. ${ }^{2}$

As for the public-private distinction, we are operating in a system in which most important public functions to an increasing extent take place on privately operated communications networks. It is not expected that states own and operate communications networks themselves, but instead that the importance and strategic interests of the state are ensured on privately owned infrastructure,

2 Convention on Cybercrime, Budapest, 23 November 2001, European Treaty Series, 185. The Convention has 60 parties, including countries from all parts of the world. 
through regulatory and licensing tools and similar. This affects EU rule-making that traditionally has acted according to established categories. EU competition law enforcement against the large, mainly US internet companies illustrate efforts to make traditional legal notions relevant in a new environment-with only partial success, as the large fines against companies such as Google (Foo, 2018) are not likely to change the way the internet economy operates in any major or lasting manner.

The phrase "technology neutrality" is well known to those working with rulemaking in technology-related field (Kamecke \& Körber, 2008). ${ }^{3}$ What it means is that rules should not prescribe specific technology but should focus on results to be obtained instead. Detailed rules may become obsolete, locking in certain technology even when better suited things may appear, or they may just be clumsy, if the technological aspects are not well understood. The principle is taken into consideration at different stages of rulemaking, in impact assessments and application (Commission Staff Working Document SWD(2013) 329 final). ${ }^{4}$ Artificial Intelligence (AI) in its multitude of forms will be a feature of almost everything we do in the future. From the simple examples that exist already in daily life, like mobile phone or online airline check-in "assistants", we will have more and more machines taking decisions not just based on exactly the input we give them but also by combining the knowledge they have in order to create new knowledge. Even enthusiasts in the AI community recognise that systems of AI cannot be introduced unchecked into society, but that possible dangers need to be considered (Yampolskiy, 2012). The dangers should be seen in the context of the kind of impact that AI can have — not just linked to some very specific task.

In law, our tools are conceptual rather than technical. Indeed, the idea of conceptual tools can be of assistance to make sense of technology neutrality in regulation and discourse. Our legal understanding of what conceptual tools to use can be usefully re-exported to the disciplines from which we took the idea of talking about tools in the first place. A conceptual tool is a way to formulate

3 Especially for telecommunications and especially in the European Union (Communication COM(1999) 539). It was incorporated into the 2002 so-called telecommunications regulatory package, reformed in 2009. It may, however, not always be well understood.

$4 \quad$ This can entail considerations like: "The participants did not have an official single view on the issues raised in the public consultation. They mainly raised the need to further assess to which extent price differentials stem from national specificities or from the inconsistent application of costing methodologies and emphasised that any proposed costing methodology should respect the principle of technological neutrality and avoid promoting a particular network roll-out" (Commission Staff Working Document SWD (2013) 329 final, p. 21). 
a mechanism to solve problems, to discuss matters. It focuses on outcomes and adapts to the circumstances and environment it is in. Todorov nicely explains why new terms and concepts can be useful: "A new concept is justifiable when it enlarges our understanding of the phenomena under investigation" (Todorov, 2006, p. 15). In the social sciences we create something that helps us systematise and categorise information - the facts on which we apply the tool may change, but the activity we perform is the same. This is the essence of technology neutrality: you use tools to do something and it is not how you do it but the result that you want to obtain that is the key.

One tool is link analysis - to visualise how parts of a legal system are connected. This allows lawmakers to identify those parts of the legal system where the smallest amount of change has the largest effect (Täks et al., 2014). This becomes more and more important as society gets more complex as there is a real danger of increase in the number of laws and rules - although fortunately legislators have become aware of this risk and tend to try to counteract it (Mandelkern et al., 2001). Any increases in the quantity of legislation creates costs for businesses and individuals. The speed of technological change already causes costs for updates and as regulation tends to lag behind technology anyway, extensive legal changes would just add an avoidable layer of complication. Thus, identifying "minimally disruptive" ways to change legislation can have serious gains. This, according to researchers working on it for copyright reform, means either to achieve substantive legal reform by changing only a small number of essential laws or otherwise to limit changes by identifying suitable candidates for reform that are minimally interlinked with the rest of the legal system (Täks et al., 2014).

Such new approaches to law-making, if consistently adopted by the EU, could provide a useful by-product of the digital single market to export, together with substantive provisions on concrete market related issues. In fact, one important way in which the EU digital single market can influence the neighbouring states is not the concrete rules, as these, in any event, must remain flexible to meet the challenge of new technologies, but it is the manner that rulemaking can occur in the new environment. EU itself is still struggling with the challenge of how to best adapt not just regulation but the mindset of legislators, regulators and market participants to the digital reality, but it has nevertheless made progress on many issues in recent years and thus can provide useful inspiration to others, like the Neighbourhood states. 


\section{The creation of a digital single market}

This article does not purport to describe or analyse the digital single market in all its complexity; rather, the brief introduction to its creation serves to support the main theme of the influence the EU rules have on countries in its Neighbourhood as far as the digital market is concerned. The issues need to be seen from a more direct and practical angle - what policies of the EU actually influence the activities of neighbourhood states? — and a larger, more fundamental one- - how has the new reality we describe above shaped not just EU rulemaking but also its ability to have an effect outside of the EU? This section outlines the direct efforts in the form of new rules and instruments that the EU has adopted and that are or will be of importance also outside of its borders.

The digital single market has been described as a market where free movement of goods, persons, services and capital is ensured, and individuals and businesses can seamlessly access and exercise online activities under conditions of fair competition, high level of consumer and personal data protection, irrespective of their nationality or place of residence. The task for regulation is to enable the single market to operate in the digital world like in the analogue one. This includes better access for consumers and businesses to online goods and services across Europe, conditions for digital networks and services to flourish and maximise the growth potential of the European digital economy (European Commission, 2015).

The subject of digital single market includes a variety of different issues, of which some are general and need to be addressed in various ways, with different instruments. Ensuring free flow of data is a fundamental issue. Another key issue is the question of the uncertain jurisdiction and what can be done to determine which country is in charge and has a real ability to enforce decisions. This is linked with managing the liability issue in a system of convergence of roles, which has led to rules on whether internet service providers should be seen as caching, hosting or acting as a mere conduit for information. Furthermore, efforts are needed to facilitate e-commerce by addressing the existing fragmentation and barriers for the digital single market, such as unjustified geo-blocking.

In recent years, the EU has given considerable priority to digital issues at many different levels and in several areas. In 2014, in his political guidelines before the European Parliament, President of the European Commission Jean-Claude Juncker stated that a connected digital single market should be a priority for Europe, and such a market would generate up to 250 billion euros of additional 
growth (Juncker, 2014). This intention materialised in the Digital Single Market Strategy for Europe established one year later. In May 2017, the mid-term review of the Strategy concluded that important steps had been taken turning political commitments into realities (European Commission, 2017) (like the adoption of a Directive on Security of Network and Information Systems (Directive (EU) 2016/1148), and the adoption of the General Data Protection Regulation).

The Estonian EU Presidency in the second half of 2017 emphasised the digital single market and various related digital issues, such as a declaration and roadmap on development of $5 \mathrm{G}$ infrastructure for mobile communications, which is essential for connected devices, so-called internet of things; an e-Governance Declaration; and a cyber security package. One key idea promoted by the Estonian Presidency was that free movement of data should be seen as a fifth freedom for the EU, in addition to the freedoms of goods, services, persons and capital. However, this idea did not lead to any concrete legislative or similar initiatives (EU, 2017).

Among the most noticeable successes of the EU digital single market, if measured in the specific implications for Member States as well as third countries, are the Regulation (EU) 910/2014 on Electronic Identities and the GDPR. The establishment of an understanding of the various roles of internet service providers (Directive 2000/31/EC, Art. 12 \& 14) may also be added to this list of concrete, noticeable measures, shaping the regulatory environment not just in the EU. Another result is the adoption in the spring of 2018 of the Regulation (EU) 2018/644 on Cross-Border Delivery Services. The Regulation makes prices for cross-border parcel delivery services more transparent and affordable and increases regulatory oversight of the EU parcel market. This is essential for e-commerce. The problems with parcel delivery have been regarded as an important discouraging factor for consumers contemplating using e-commerce from other Member States. The Regulation should allow consumers and companies (including SMEs), to buy and sell products and services online more easily. The Regulation is the third pillar of EU's efforts to boost e-commerce together with Regulation (EU) 2018/302 addressing unjustified geo-blocking and other forms of discrimination based on customers' nationality, place of residence or place of establishment as well as enhanced rules on consumer protection provisions.

The EU has furthermore been quite successful as far as start-ups and innovative companies are concerned, even if this varies quite a lot between Member States. The creation of the digital single market includes creation of a clear and stable legal environment to stimulate innovation, tackle market fragmentation and provide fair 
and balanced conditions (Communication $\operatorname{COM}(2017) 228$ final, p. 3). The digital single market is not just a collection of rules on technical - digital - matters, but rather a context for new technologies. Many of the concrete results of recent efforts will only be fully known in some years' time. For instance, the rules on geo-blocking will be evaluated within two years after their entry into force to determine what actual results have been achieved for electronically supplied services using copyrighted content (downloadable music, e-books, software, online games) and for services, for example, in the audio-visual sector.

\section{Neighbourhood states and the digital single market}

The European Neighbourhood Policy (ENP) was established in 2004, aiming to be a framework for the relations between the EU and its eastern and southern neighbours. The general purpose was to achieve the closest possible political association and the greatest possible degree of economic integration (COM(2003) 104 final). This policy has been revised several times (most recently in November 2015), focusing on differentiation among partner countries in order to provide adequate flexibility and enhanced sharing of responsibility. In support of its partners, the European Neighbourhood Instrument (ENI) is funded with 15 billion euros in the period 2014-2020 (EU Neighbours, 2017). Georgia is a long-time partner of the ENP and the two sides have signed an Association Agreement, which entered into force on 1 July 2016, to be complemented by a Deep and Comprehensive Free Trade Area Agreement. The EU is Georgia's most important trading partner, which means that around $29 \%$ of the total foreign trade of Georgia is with the EU (European Commission, 2015).

As described above, the digital single market is evidently imposing obligations and establishing rights within the EU. However, its impact is felt even outside, either through the required harmonisation in order to continue trade relations, or domestically, through enhancing positive elements of e-governance and avoiding negative effects of insufficient regulatory and other adaptation to the digital society. EU support has led to some successes, for example in the area of e-Governance where Georgian reforms - supported by an EU twinning project — have been used as models for the region (DEA, 2018).

As far as the external implications are concerned, it is a well-known fact that the effect of harmonisation through the relationships that EU is forming with countries such as the ENP states, entails a more widespread "soft" Europeanisation in addition to that which has to be harmonised for specific reasons. Grabbe 
says that when European norms have become so embedded in national policy frameworks, policy-making structures and discourse that people stop referring to "EU policies" is when the process has been really successful (Grabbe, 2006, p. 205). However, policy transfers from one country - or organisation, collection of countries - to others require a clear and well-stated policy, as otherwise there may be problems of diffuseness raising the question what it actually is that should be done in order to implement the "imported" policy. The EU has been criticised for its lack of clear institutional templates or inconsistencies in advice on how to implement the EU acquis. Grabbe mentions as an example the difficulties for candidate states to implement the acquis related to the Schengen area, as this was in a process of important change at the same time (Grabbe, 2006, p. 188). In the fast-moving and complex world of digital technologies, such weaknesses can be exacerbated. The EU has been known to avoid strategic decision-making, as a consequence of its nature as a body that incorporates compromises between Member States in its decision-making process. This is a source of uncertainty for its policy transfer. The EU has often been criticised for being unable to exercise the full potential of its ability to shape public policy (Grabbe, 2006, pp. 199-200).

Despite EU having had to surmount various crises, the attraction of the EU for potential members as well as other states, especially in the Neighbourhood, remains important. For the ENP partners, the chance to align oneself with the $\mathrm{EU}$ is a clear way to show aspirations to be part of the civilised club of nations (Patalakh, 2017, p. 151). As pointed out in Section 2 above, what internet brings to society is something that goes far beyond new ways of communication, simplifying trade or providing new ways to buy goods and services. The increasing digitalisation affects most areas of society. Not least does it entail, or perhaps rather "should entail", changes in the legal and regulatory sphere, as the development has not kept pace with technological progress. Rulemaking in the "digital world" differs from traditional methods in several ways. If a state or an organisation, such as the EU, wishes to be leader in regulatory activities for the digital environment, it needs to be well aware of the new challenges for how rules are to be made. The environment for both making rules and applying them has become interdisciplinary.

Most ENP-related agreements are linked with traditional trade issues. Digital aspects are too new to form an important part of ENP interest. Also, these policies are still being shaped within the EU, which consequently is less prone to introduce them to other states. However, developments are fast, and the situation changes by the day. As GDPR has shown, developments in the digital sphere affect important traditional trade issues for third countries, not least the 
Neighbourhood states. The fact that the EU's message on the finer details and the workings of the digital single market appears less clear and distinct than on traditional trade issues does not mean that it is any less important for ENP states. Quite the opposite - this is an area where countries with relations with the EU have a good opportunity to play an important part from the start of the development of essential new policies.

\section{Conclusions}

The digital single market is an internal process of the EU with huge implications within and without its territory. However, as it is often stated, the digital world is characterised as a world without borders, without regard to territory and distances. As such, the impact of relevant policies of the EU is diffused everywhere. Such impact is felt the more, the bigger trade relationships there are between the state in question and the EU. Georgia as well as other Neighbourhood Policy partners invest a lot in increasing all aspects of their relationship with the EU in view of a possible future membership. Although the content of the agreements between the EU and Neighbourhood Policy partners focuses mostly on physical goods and services, digitalisation has implications on regulatory and political aspects, which should be dealt with in anticipation before issues arise that may directly harm the trade relationship.

We have pointed out the manifold ways in which the digital society differs qualitatively from other forms of the single market. The digital single market entails not just the need for harmonisation with certain specific regulations, although this is important as well, notably with the GDPR. In addition, rulemaking and enforcement activities need to understand and be open to challenges of the "borderless" market. At the same time, this should not be seen as something negative: countries can make use of positive aspects of the absence of physical borders. A close digital harmonisation may be a shortcut to even closer cooperation and could help prevent potential hick-ups. Consequently, the Neighbourhood states should pay close attention to the digital developments in the EU. This attention should be up-stream as well as down-stream: Up-stream, the institutional structures of the association agreement could be the podium for Georgia's expression of its priorities, worries and interests, already while the EU is shaping its relevant policies. Obviously, the impact of its voice is limited, but nevertheless it can be used in order to express the country's position and fears throughout the evolution of new rules. The fast-moving and constantly evolving 
nature of the digital society in general means that, in fact, any country-even smaller ones - can manage to get attention for their ideas, given that the quality of the comments and ideas is good and demonstrates expertise and genuine interest in the matter in question. The impact of Estonian ideas on digital matters within the EU is an illustration of this. Georgia should consider if and how it has potential to become a digital leader among the Neighbourhood Policy partners. Increased attention to the issue in higher education would be one important step in this direction.

Down-stream, Georgia is in the midst of a formidable task of adjusting its legislation sufficiently to the digital market requirements of the EU, both to avoid possible obstruction of trade and to enhance a soft of form Europeanisation in its regulatory and legislative systems. As discussed above, the digital single market should not only be viewed as a trade-related issue. Georgia should grasp the opportunity to use digital developments in order to improve societal issues, like combatting corruption, improving transparency and accountability as well as enhancing protection of personal data. The challenges and opportunities provided by e-Governance for better law-making and improvement of the quality of the society are perhaps the best aspects of this form of Europeanisation, constantly enhanced as the digital single market develops. Georgia should not lose this opportunity.

Katrin Nyman-Metcalf is a adjunct professor specialising in Law and Technology at Tallinn University of Technology, Estonia, and programme director of Research and Legal Aspects of the Estonian e-Governance Academy. For the past 20 years, she has been active globally as consultant primarily in the area of communications law in the broad sense, including ICT regulation, privacy and data protection, media law, e-governance and cyber issues. She has worked in more than 50 countries, including post-conflict and developing states, with legal analysis and drafting, professional training and creation of regulatory authorities. Her PhD (Uppsala University, 1999) is on the law of outer space and she is Chairman of the International Relations Committee of the European Space Agency.

loannis Papageorgiou is an associate professor at the School of Political Sciences of the Aristotle University of Thessaloniki, Greece, teaching the history of European integration, EU's political system and comparative politics. He is a lawyer and political scientist (degree in law from the University of Athens, MA in comparative politics from the University of Paris I and MA in development cooperation from the Université Libre de Bruxelles). His PhD (2001) from the ULB dealt with regional integration in Central America. Papageorgiou has also worked as an independent expert in several international projects with accession countries in the areas of migration and asylum since 2003. During the Cyprus Presidency of the Council of the EU in 2012, he acted as the Chair of the Asylum Working Party 
in the Council of Ministers of the EU. Between 2016 and 2017 he worked in the Policy Department for Citizens' Rights and Constitutional Affairs of the European Parliament in Brussels, dealing with the institutional aspects of Brexit and on issues of civil liberties. His academic research covers issues of European integration, other regional integration processes, the role of regional courts in international democracy, immigration policy and international humanitarian and refugee law.

\section{References}

Caliskan, E. \& Peterson, R. (2013), 'Technical defence methods, tools, techniques and effects,' in K. Ziolkowski (ed.) Peacetime Regime for State Activities in Cyberspace, Tallinn: NATO Cooperative Cyber Defence Centre of Excellence, pp. 61-101.

CEN (2018), 'Supporting Public Policies and Legislation: New Approach and other Directives,' CEN, European Committee for Standardization. Retrieved from https://www.cen.eu/work/supportLegislation/Directives/Pages/default.aspx [accessed 19 Jul 2018]

Commission Staff Working Document SWD(2013) 329 final: Impact Assessment, Accompanying the document Commission Recommendation on consistent nondiscrimination obligations and costing methodologies to promote competition and enhance the broadband investment environment, 11.9.2013.

Communication $\operatorname{COM}(2017) 228$ final from the Commission to the Council, the European Economic and Social Committee and the Committee of the Regions on the Mid-Term Review on the implementation of the Digital Single Market Strategy “A Connected Digital Single Market for All”, 10.5.2017.

Communication $\operatorname{COM}(2003) 104$ final from the Commission to the Council and the European Parliament "Wider Europe - Neighbourhood: A New Framework for Relations with our Eastern and Southern Neighbours", 11.3.2003.

Communication $\operatorname{COM}(1999) 539$ from the Commission to the Council, the European Parliament, the Economic and Social Committee and the Committee of the Regions, "Towards a new framework for Electronic Communications infrastructure and associated services", The 1999 Communications Review, 10.11.1999.

Communication COM(2015) 192 final from the Commission to the European Parliament, the Council, the European Economic and Social Committee and the Committee of the Regions "A Digital Single Market Strategy for Europe", 6.5.2015.

DEA (2018), 'Georgian reforms in e-Governance have been presented as an example of success at the international conference,' Data Exchange Agency, 5 April. Retrieved from http://www.dea.gov.ge/?action=news\&news_id=131\&lang=eng [accessed 19 Jul 2018] 
Directive 2000/31/EC of the European Parliament and of the Council of 8 June 2000 on certain legal aspects of information society services, in particular electronic commerce, in the Internal Market ('Directive on electronic commerce'), $O J \mathrm{~L} 178,17.7 .2000$.

Directive (EU) 2016/1148 of the European Parliament and of the Council of 6 July 2016 concerning measures for a high common level of security of network and information systems across the Union, $O J$ L 194, 19.7.2016.

Duvivier, K. K. (2013), 'E-Legislating,' Oregon Law Review, vol. 92, no. 9. https:// doi.org/10.2139/ssrn.2230124.

Dutt, P. \& Kerikmäe, T. (2014), 'Concepts and Problems Associated with eDemocracy,' in T. Kerikmäe (ed.) Regulating eTechnologies in the European Union, Cham: Springer International Publishing, pp. 285-324.

EPRS (2014), The Cost of Non-Europe in the Single Market: Study, Brussels: European Parliament Research Service, PE510.981. https://doi.org10.2861/57536

EU (2017), 'Summary of the Estonian Presidency of the Council of the European Union,' Eu2017.ee. Retrieved from https://www.eu2017.ee/node/5392.html [accessed 19 Jul 2018]

EU Neighbours (2017), 'The European Neighbourhood Instrument (ENI), EU: A major donor.' Retrieved from https://www.euneighbours.eu/en/policy/europeanneighbourhood-instrument-eni\#donor [accessed Oct 2018]

European Commission (2015), EU-Georgia Trade Deep and Comprehensive Free Trade Area (DCFTA) Factsheet: Reforms that benefit people and business. Retrieved from http://trade.ec.europa.eu/doclib/docs/2015/may/tradoc_153435. pdf [accessed Oct 2018]

European Commission (2017), 'Digital Single Market Strategy: - mid-term review.' Retrieved from https://eur-lex.europa.eu/content/news/digital_market.html [accessed 19 Jul 2018]

Foo, Y. C. (2018), 'Europe hits Google with record \$5 billion antitrust fine, appeal ahead,' Reuters Business News, 18 July. Retrieved from https://www.reuters.com/ article/us-eu-google-antitrust/europe-hits-google-with-record-5-billion-antitrustfine-appeal-ahead-idUSKBN1K80U8 [accessed 19 Jul 2018]

Geiss, R. \& Lahmann, H. (2013), 'Freedom and security in cyberspace: The focus away from military responses toward non-forcible countermeasures and collective threat-prevention,' in K. Ziolkowski (ed.) Peacetime Regime for State Activities in Cyberspace, Tallinn: NATO Cooperative Cyber Defence Centre of Excellence, pp. $621-658$.

Grabbe, H. (2006), The EU's Transformative Power: Europeanization through Conditionality in Central and Eastern Europe, London: Palgrave MacMillan. https://doi.org/10.1057/9780230510302 
Horvathy, B. (2017), 'Value promotion and Europeanisation by EU trade agreements,' Bratislava Law Review, vol. 1/2017, pp. 84-94.

Juncker, J.-C. (2014), A New Start for Europe: My Agenda for Jobs, Growth, Fairness and Democratic Change, Political Guidelines for the next European Commission, Opening Statement in the European Parliament Plenary Session, 15 July. Retrieved from https://ec.europa.eu/commission/sites/beta-political/files/juncker-politicalguidelines-speech_en.pdf [accessed 19 Jul 2018]

Kamecke, U. \& Körber, T. (2008), 'Technological neutrality in the EC regulatory framework for electronic communications: a good principle widely misunderstood,' European Competition Law Review Issue, no. 5, pp. 330-337.

Mandelkern, D. et al. (2001), Mandelkern Group on Better Regulation: Final Report, Brussels, 13.11.2001.

Morgan, B. \& Yeung, K. (2007), An Introduction to Law and Regulation, Cambridge: Cambridge University Press. https://doi.org/10.1017/CBO9780511801112

Nyman Metcalf, K. (2014), 'E-Governance in law and by law: the legal framework of e-governance,' in T. Kerikmäe (ed.) Regulating eTechnologies in the European Union, Cham: Springer International Verlag, pp. 37-51.

Nyman Metcalf, K. (2018, forthcoming), 'The role of research for secure digitalisation,' in Law and Informatics Nordic Yearbook.

Nyman Metcalf, K. \& Täks, E. (2013), 'Simplifying the law - can ICT help us?' International Journal of Law and Information Technology, vol. 21, no. 3, pp. 239-268. https://doi.org/10.1093/ijlit/eat003

Patalakh, A. (2017), 'EU soft power in the Eastern Neighbourhood and the Western Balkans in the context of crises,' Baltic Journal of European Studies, vol. 7, no. 2 (23), pp. 148-167. https://doi.org/10.1515/bjes-2017-0014

Regulation (EU) 910/2014 of the European Parliament and of the Council of 23 July 2014 on electronic identification and trust services for electronic transactions in the internal market and repealing Directive 1999/93/EC, OJ, L 257/73, 28.8.2014.

Regulation (EU) 2016/679 of the European Parliament and of the Council of 27 April 2016 on the protection of natural persons with regard to the processing of personal data and on the free movement of such data, and repealing Directive 95/46/EC (General Data Protection Regulation), OJ L 119, 4.5.2016.

Regulation (EU) 2018/302 of the European Parliament and of the Council of 28 February 2018 on addressing unjustified geo-blocking and other forms of discrimination based on customers' nationality, place of residence or place of establishment within the internal market and amending Regulations (EC) No 2006/2004 and (EU) 2017/2394 and Directive 2009/22/EC, OJ L 60I, 2.3.2018.

Regulation (EU) 2018/644 of the European Parliament and of the Council of 18 April 2018 on cross-border parcel delivery services, $O J$ L 112, 2.5.2018. 
Täks, E.; Rull, A.; Säär, A. \& Schafer, B. (2014), Report on a Computer Assisted Copyright Reform Observatory CREATe Working Paper, 2014/11. Retrieved from https://zenodo.org/record/12431/files/CREATe-Working-Paper-2014-11.pdf [accessed 19 Jul 2018]. https://doi.org/10.5281/zenodo.12431

Todorov, J. C. (2006), 'The metacontingency as a conceptual tool,' Behavior and Social Issues, vol. 15, no. 1, pp. 92-94. https://doi.org/10.5210/bsi.v15i1.347

Yampolskiy, R. V. (2012), 'AI-complete CAPTCHAs as zero knowledge proofs of access to an artificially intelligent system,' ISRN Artificial Intelligence, vol. 2012. http://doi.org/10.5402/2012/271878 